\title{
Supramolecular hydrogen-bonding networks in the 1-(diaminomethylenene)thiouron-1-ium 4-hydroxybenzoate, 3,4-dihydroxybenzoate and 3,4,5-trihydroxybenzoate monohydrate crystals
}

\author{
Genivaldo Julio Perpétuo ${ }^{\text {a }}$, Jan Janczak ${ }^{\mathrm{b}, *}$ \\ ${ }^{a}$ Departamento de Física, Instituto de Ciências Exatas e Biológicas, Universidade Federal de Ouro Preto, 35400-000 Ouro Preto, MG, Brazil \\ ${ }^{\mathrm{b}}$ Institute of Low Temperature and Structure Research, Polish Academy of Sciences, PO Box 1410, 50950 Wrocław, Poland
}

\section{A R T I C L E I N F O}

\section{Article history:}

Received 2 January 2013

Received in revised form 7 March 2013

Accepted 7 March 2013

Available online 16 March 2013

\section{Keywords:}

1-(Diaminomethylenene)thiourea

4-Hydroxybezoate

3,4-Dihydroxybenzoate

3,4,5-Trihydroxybenzoate

Crystal structure

Vibrational spectra

\begin{abstract}
A B S T R A C T
Three crystals of 1-(diaminomethylene)thiouron-1-ium 4-hydroxybenzoate (1), 1-(diaminomethylene)thiouron-1-ium 3,4-dihydroxybenzoate (2) and 1-(diaminomethylene)thiouron-1-ium 3,4,5-trihydroxybenzoate monohydrate (3) were grown using a solution growth technique. The conformation of the 1-(diaminomethylene)thiouron-1-ium cation in these structures is very similar and exhibits twisting conformation. The planar $\mathrm{COO}^{-}$group of the oppositely charged components of the crystals, i.e. 4hydroxybenzoate, 3,4-dihydroxybenzoate and 3,4,5-trihydroxybenzoate, are slightly inclined to the benzene ring. Both oppositely charged units, i.e. the 1-(diaminomethylene)thiouron-1-ium cation and respective mono- di- or trihydroxybenzoate anions, interact via $\mathrm{R}_{2}{ }^{2}(8)$ hydrogen bonding motif forming 1:1 supramolecular complexes. These supramolecular complexes interact each other via $\mathrm{N}-\mathrm{O}$ or $\mathrm{O}-\mathrm{H} \cdots \mathrm{O}$ hydrogen bonds forming the 3D-hydrogen bonding networks. These compounds were also characterised by the IR-spectroscopy. The characteristic bands of the $\mathrm{NH}_{2}, \mathrm{OH}, \mathrm{C}=\mathrm{S}, \mathrm{COO}^{-}$as well as of the skeletal groups are discussed.
\end{abstract}

(c) 2013 Elsevier B.V. All rights reserved.

\section{Introduction}

1-(Diaminomethylenene)thiourea is a tautomeric form of commercially available 2-imino-4-thiobiuret (Scheme 1) as has been shown by the X-ray single crystal analysis [1]. Both tautomers are already considered to be useful building blocks in the crystal engineering, since they contain active hydrogen bonding sites. Additionally, both tautomers can act as $N, N$ - or $N, S$-coordinating ligands forming several types of complexes with metal ions [2-4]. The 1-(diaminomethylenene)thiourea contains the basic $\mathrm{N}$ atom with the lone-pair of electrons that can accept the proton forming positively charged unit that with the oppositely charged counterions form salts with extended hydrogen-bonding networks in solids [5-13].

To explore the possibility of 1-(diaminomethylenene)thiourea forming predictable hydrogen-bonding networks, it would be useful to observe its behaviour towards other known building blocks like carboxylic acids that are widely used in this context [14]. In particular, the supramolecular aggregation pattern of 1-(diaminomethylenene)thiourea with tartaric acid and its deuterated analogue are examples of supramolecular hydrogen-bonding salts that can be utilised as materials for non-linear optic [15].

\footnotetext{
* Corresponding author. Tel.: +48 71343 5021; fax: +48 713441029 .

E-mail address: j.janczak@int.pan.wroc.pl (J. Janczak).
}

In the present work, we used the 4-hydroxybenzoic, 3,4-dihydroxybenzoic and 3,4,5-trihydroxybenzoic acids (Scheme 1c-e) to explore the possibility of 1-(diaminomethylenene)thiourea to form the new materials with extended hydrogen-bonding patterns in solids. The compounds were also characterised by vibrational spectroscopy, and the results are discussed and compared with the data obtained for a neutral 1-(diaminomethylene)-thiourea molecule.

\section{Experimental}

All materials were commercially available and used as received. Elemental analysis was carried out with a Perkin-Elmer 240 elemental analyser.

Preparation of 1-(diaminomethylene)thiouron-1-ium 4hydroxybenzoate (1), 1-(diaminomethylene)thiouron-1-ium 3,4dihydroxybenzoate (2) and 1-(diaminomethylene)thiouron-1-ium 3,4,5-trihydroxybenzoate monohydrate (3).

Commercially available 2-imino-4-thiobiuret (Aldrich, CAS No. 2114-02-05), which is in fact the tautomeric form 1-(diaminomethylene)thiourea and the respective acid, 4-hydroxybenzoic acid (Aldrich, purity of 99\%), 3,4-dihydroxybenzoic acid (Aldrich, purity of 99\%) and 3,4,5-trihydroxybenzoic acid (Aldrich, purity of 99\%), were added to hot water in a molar proportion of $1: 1$. When the solution became homogeneous it was cooled slowly and kept at room temperature. After several days, transparent colourless 
<smiles></smiles>

(a)<smiles>O=C(O)c1ccc(O)cc1</smiles>

(c)<smiles>CN=C(N)N</smiles>

(b)<smiles>O=C(O)c1ccc(O)c(O)c1</smiles>

(d)<smiles>O=C(O)c1cc(O)c(O)c(O)c1</smiles>

(e)
Scheme 1. 2-Imino-4-thiobiuret (a) and 1-(diaminomethylene)thiourea (b), and 4hydroxybezoic acid (c), 3,4-dihydroxybenzoic acid (d) and 3,4,5-trihydroxybenzoic acid (e).

crystals of $\mathrm{C}_{7} \mathrm{H}_{5} \mathrm{O}_{3} \cdot \mathrm{C}_{2} \mathrm{H}_{7} \mathrm{~N}_{4} \mathrm{~S}(\mathbf{1}), \mathrm{C}_{7} \mathrm{H}_{5} \mathrm{O}_{4} \cdot \mathrm{C}_{2} \mathrm{H}_{7} \mathrm{~N}_{4} \mathrm{~S}(\mathbf{2})$ and $\mathrm{C}_{7} \mathrm{H}_{5} \mathrm{O}_{5-}$ . $\mathrm{C}_{2} \mathrm{H}_{7} \mathrm{~N}_{4} \mathrm{~S} \cdot \mathrm{H}_{2} \mathrm{O}$ (3) formulas were formed. Analysis: calculated for crystals (1): C, 42.18; $\mathrm{H}, 4.72 ; \mathrm{N}, 21.86 ; \mathrm{O}, 18.73$ and $\mathrm{S}, 12.51 \%$, found: C. 42.25; H, 4.75; N, 21.78; O 18.70, and S, 12.52\%; calculated for crystals $(2)$ : C, 36.70; H, 4.44; N, 20.58; O, 23.50 and S, $11.78 \%$, found: C. 36.85; $\mathrm{H}, 4.39 ; \mathrm{N}, 20.68 ; \mathrm{O} 23.78$, and $\mathrm{S}$, $11.68 \%$; calculated for crystals (3): C, 35.29; H, 4.61; N, 18.29; O, 31.34 and S, 10.47\%. Found: C. $35.41 ; \mathrm{H}, 4.58 ; \mathrm{N}, 18.18 ; \mathrm{O}$ 31.48 , and $\mathrm{S}, 10.35 \%$.

\subsection{X-ray data collection}

X-ray intensity data for the crystals were collected using graphite monochromatic MoK $\alpha$ radiation on a four-circle $\kappa$ geometry KUMA KM-4 diffractometer with a two-dimensional area CCD detector. The $\omega$-scan technique with $\Delta \omega=1.0^{\circ}$ for each image was used for data collection. The 930 images for six different runs covering over $99 \%$ of the Ewald sphere were performed. One image was used as a standard after every 50 images for monitoring of the crystal stability and the data collection. No correction on the relative intensity variations was necessary. Data collections were made using the CrysAlis CCD program [16]. Integration, scaling of the reflections, correction for Lorentz and polarisation effects and absorption corrections were performed using the CrysAlis Red program [16]. The structures were solved by the direct methods using SHELXS-97 and refined using SHELXL-97 program [17]. The hydrogen atoms involving in the hydrogen bonds were located in difference Fourier maps and were refined. The hydrogen atoms joined to aromatic carbon atoms were introduced in their geometrical positions. The final difference Fourier maps showed no peaks of chemical significance. Details of the data collection parameters, crystallographic data and final agreement parameters are collected in Table 1. Visualisations of the structures were made with the Diamond 3.0 program [18]. Selected geometrical parameters are listed in Table 2 and the geometry of hydrogen bonding interactions is collected in Table 3.

\subsection{Vibrational spectra measurements}

The vibrational measurements were carried out at room temperature. The Fourier transform infrared spectrum was recorded from Nujol mulls between 4000 and $400 \mathrm{~cm}^{-1}$ on a Bruker IFS 113V FTIR. Resolution was set up to $2 \mathrm{~cm}^{-1}$.

\section{Results and discussion}

Good quality single crystals of 1-(diaminomethylene) thiouron1-ium 4-hydroxybenzoate (1), 1-(diaminomethylene) thiouron1-ium 3,4-dihydroxybenzoate (2) and 1-(diaminomethylene) thiouron-1-ium 3,4,5-trihydroxybenzoate monohydrate (3) suitable for the X-ray single crystal analysis were obtained from water solutions at ambient temperature. The X-ray single crystal analyses show that the carboxyl group of the acids is deprotonated, i.e. it is transferred to the central N1 atom of 1-(diaminomethylene)thiourea molecule forming 1-(diaminomethylene) thiouron-1-ium

Table 1

Crystallographic data for $\mathbf{1}, \mathbf{2}$, and $\mathbf{3}$.

\begin{tabular}{|c|c|c|c|}
\hline & 1 & 2 & 3 \\
\hline Formula & $\mathrm{C}_{9} \mathrm{H}_{12} \mathrm{~N}_{4} \mathrm{O}_{3} \mathrm{~S}$ & $\mathrm{C}_{9} \mathrm{H}_{12} \mathrm{~N}_{4} \mathrm{O}_{4} \mathrm{~S}$ & $\mathrm{C}_{9} \mathrm{H}_{14} \mathrm{~N}_{4} \mathrm{O}_{6} \mathrm{~S}$ \\
\hline Molecular weight & 256.29 & 272.29 & 306.30 \\
\hline Temperature $(\mathrm{K})$ & $295(2)$ & $295(2)$ & $296(2)$ \\
\hline Crystal system & monoclinic & monoclinic & monoclinic \\
\hline Space group & $\mathrm{P} 2 / \mathrm{c}$ (No. 14) & $\mathrm{P} 21 / \mathrm{c}$ (No. 14 ) & P $22_{1} / \mathrm{c}$ (No. 14 ) \\
\hline$a(\AA)$ & $10.736(1)$ & $11.609(3)$ & $12.217(2)$ \\
\hline$b(\AA)$ & $9.615(1)$ & $9.981(2)$ & $9.1230(18)$ \\
\hline$c(\AA)$ & $11.039(2)$ & $10.930(2)$ & $12.717(3)$ \\
\hline$\beta\left(^{\circ}\right)$ & $92.58(1)$ & $93.12(1)$ & $115.52(1)$ \\
\hline$V\left(\AA^{3}\right)$ & $1138.4(3)$ & $1264.6(4)$ & $1279.1(4)$ \\
\hline$Z$ & 4 & 4 & 4 \\
\hline$D_{\text {calc }} / D_{\exp }\left[\mathrm{g} \mathrm{cm}^{-1}\right]$ & $1.495 / 1.49$ & $1.430 / 1.43$ & $1.591 / 1.59$ \\
\hline$\mu\left(\mathrm{mm}^{-1}\right)$ & 0.288 & 0.269 & 0.287 \\
\hline Crystal size $\left(\mathrm{mm}^{3}\right)$ & $0.35 \times 0.29 \times 0.24$ & $0.34 \times 0.28 \times 0.22$ & $0.38 \times 0.34 \times 0.28$ \\
\hline$T_{\min } / T_{\max }$ & $0.9377 / 0.9089$ & $0.9442 / 0.9194$ & $0.9321 / 0.9042$ \\
\hline Total/unique/Obs refls & $15309 / 2962 / 1695$ & $13597 / 3079 / 2412$ & $14454 / 3156 / 2456$ \\
\hline$R_{\text {int }}$ & 0.0451 & 0.0190 & 0.0194 \\
\hline$R\left[F^{2}>2 \sigma\left(F^{2}\right)\right]^{\mathrm{a}}$ & 0.0373 & 0.0346 & 0.0341 \\
\hline$w R\left[F^{2} \text { all refls }\right]^{\mathrm{b}}$ & 0.0871 & 0.0961 & 0.0945 \\
\hline$S$ & 1.001 & 1.000 & 1.007 \\
\hline \multicolumn{4}{|c|}{ Residual electron density, } \\
\hline$\Delta \rho_{\max }, \Delta \rho_{\min }\left(\mathrm{e} \cdot \AA^{-3}\right)$ & $0.182 ;-0.188$ & $0.276 ;-0.270$ & $0.272 ;-0.290$ \\
\hline
\end{tabular}


Table 2

Comparison of the bond lengths $(\AA)$ and angles $\left(^{\circ}\right)$ for 1-(diaminomethylene) thiouron-1-ium 4-hydroxybenzoate (1), 3,4-dihydroxybenzoate (2) and 3,4,5-trihydroxybenzoate monohydrate (3).

\begin{tabular}{|c|c|c|c|}
\hline & 1 & 2 & 3 \\
\hline \multicolumn{4}{|c|}{ 1-(Diaminomethylene) thiouron-1-ium cation } \\
\hline $\mathrm{C} 1-\mathrm{S} 1$ & $1.6632(15)$ & $1.6802(13)$ & $1.6906(14)$ \\
\hline $\mathrm{C} 1-\mathrm{N} 1$ & $1.3708(19)$ & $1.3970(15)$ & $1.3763(17)$ \\
\hline $\mathrm{C} 1-\mathrm{N} 2$ & $1.3130(20)$ & $1.3666(16)$ & $1.3086(18)$ \\
\hline $\mathrm{C} 2-\mathrm{N} 1$ & $1.3590(18)$ & $1.4154(15)$ & $1.3599(17)$ \\
\hline $\mathrm{C} 2-\mathrm{N} 3$ & $1.3042(18)$ & $1.3199(15)$ & $1.2993(18)$ \\
\hline $\mathrm{C} 2-\mathrm{N} 4$ & $1.3057(18)$ & $1.3287(15)$ & $1.3142(18)$ \\
\hline $\mathrm{N} 2-\mathrm{C} 1-\mathrm{N} 1$ & $112.20(13)$ & $114.10(11)$ & $112.83(12)$ \\
\hline $\mathrm{N} 2-\mathrm{C} 1-\mathrm{S} 1$ & $122.65(13)$ & $121.62(9)$ & $122.05(10)$ \\
\hline $\mathrm{N} 1-\mathrm{C} 1-\mathrm{S} 1$ & $125.15(12)$ & $124.27(9)$ & $125.12(10)$ \\
\hline $\mathrm{C} 2-\mathrm{N} 1-\mathrm{C} 1$ & $131.05(13)$ & $131.56(10)$ & $129.83(12)$ \\
\hline $\mathrm{N} 4-\mathrm{C} 2-\mathrm{N} 3$ & $120.48(15)$ & 119.19(12) & $120.97(13)$ \\
\hline $\mathrm{N} 4-\mathrm{C} 2-\mathrm{N} 1$ & $116.53(13)$ & 117.18(10) & $115.96(13)$ \\
\hline $\mathrm{N} 3-\mathrm{C} 2-\mathrm{N} 1$ & $122.99(14)$ & 123.63(11) & $123.07(12)$ \\
\hline $\mathrm{C} 1-\mathrm{N} 1-\mathrm{C} 2-\mathrm{N} 3$ & $-3.11(11)$ & $-178.25(11)$ & $-7.27(12)$ \\
\hline \multicolumn{4}{|c|}{ 2-Hydroxy-, 3,4-dihydroxy- or 3,4,5-tri-hydroxybenzoate anion } \\
\hline $\mathrm{C} 3-\mathrm{O} 1$ & $1.2412(16)$ & $1.2619(14)$ & $1.2611(15)$ \\
\hline $\mathrm{C} 3-\mathrm{O} 2$ & $1.2653(16)$ & $1.2753(14)$ & $1.2663(15)$ \\
\hline $\mathrm{C} 3-\mathrm{C} 4$ & $1.489(2)$ & $1.5450(16)$ & $1.4969(18)$ \\
\hline $\mathrm{C} 6-\mathrm{O} 6$ & & $1.3845(14)$ & $1.3727(15)$ \\
\hline $\mathrm{C} 7-\mathrm{O} 7$ & $1.3599(19)$ & $1.4051(15)$ & $1.3604(16)$ \\
\hline $\mathrm{C} 8-\mathrm{O} 8$ & & & $1.3702(15)$ \\
\hline $\mathrm{O} 1-\mathrm{C} 3-\mathrm{O} 2$ & $122.70(14)$ & $121.99(11)$ & $122.59(12)$ \\
\hline
\end{tabular}

cation. In all crystals investigated here the oppositely charged units, i.e. 1-(diaminomethylene) thiouron-1-ium cation and 4hydroxybezoate $(-)$, 3,4-dihydroxybenzoate(-) or 3,4,5-trihydroxybenzoate $(-)$ anions interact each other via two almost linear hydrogen bonds with a graph of $\mathrm{R}_{2}{ }^{2}(8)$ as illustrate Fig. $1 \mathrm{a}$, b and c. The graph sets was used according to Etter notification [19]. In 1 and 2 , the $\mathrm{R}_{2}^{2}(8)$ motif is formed by donation to the $\mathrm{COO}^{-}$group of 4-hydroxybenzoate or 3,4-dihydroxybenzoate anions from the amino groups bonded to the $\mathrm{C} 2$ atom (Fig. 1a and b, Table 3), whereas in the crystal 3 these amine groups do not participate in a similar motif. The $\mathrm{R}_{2}{ }^{2}(8)$ motif is created via participation of the iminium group (N1) and amine group (N2) bonded to $\mathrm{C} 1$ atom of the cation as a donors and the $\mathrm{O} 1$ and $\mathrm{O} 2$ atoms of carboxylate group of the anion as an acceptor (Fig. 1c).

The conformation of the 1-(diaminomethylene)thiouron-1-ium cation in these crystals is only slightly deviated from a planar configuration. Both arms of the cation are slightly oppositely rotated around the $\mathrm{C}-\mathrm{N}$ bonds involving the central $\mathrm{N} 1$ atom. The dihedral angle between the $\mathrm{N} 1 / \mathrm{C} 1 / \mathrm{S} 1 / \mathrm{N} 2$ and $\mathrm{N} 1 / \mathrm{C} 2 / \mathrm{N} 3 / \mathrm{N} 4$ planes is equal to $2.0(2)^{\circ}, 5.1(2)^{\circ}$ and $6.2(2)^{\circ}$ in the crystals 1,2 and 3 , respectively. The rotation of the arms around the $\mathrm{C}-\mathrm{N} 1$ bonds in these structures is significantly smaller than that in the crystal of neutral 1-(diaminomethylene)thiourea molecule $\left(22.2(1)^{\circ}\right)$ [1]. The gasphase conformation of the 1-(diaminomethylene)thiouron-1-ium cation as show the $a b$ initio MO calculations is also twisted with similar dihedral angle of $6.2^{\circ}$ [5]. The available data on 1-(diaminomethylene)thiouron-1-ium salts (Table 4) show that the 1(diaminomethylene)thiouron-1-ium cation twisting may differ and depends on the anions and is undoubtedly dependent on the hydrogen bonding system formed by the oppositely charged units. Protonation of the neutral 1-(diaminomethylene)thiourea molecule causes a decrease of the steric effect of the lone pair of electron at the central $\mathrm{N} 1$ atom and reduce the twisting angle between the arms of the 1-(diaminomethylene)thiouron-1-ium cation, when compared with that of neutral molecule. The C1-S1 bond (Table 2 ) is slightly longer than the typical $\mathrm{C}=\mathrm{S}$ double bond as observed in the thioformaldehyde $\mathrm{CH}_{2} \mathrm{C}=\mathrm{S}(1.6019(8) \AA)$ [20], which represents $100 \%$ double-bond character, and is slightly
Table 3

Hydrogen-bond geometry, the second, third and fourth columns concern the length ( $\AA$ ) and the fifth column represents the angles $\left({ }^{\circ}\right)$.

\begin{tabular}{|c|c|c|c|c|}
\hline \multicolumn{5}{|c|}{ 1-(Diaminomethylene) thiouron-1-ium 4-hydroxybenzoate $(\mathbf{1})^{\mathrm{a}}$} \\
\hline$D-\mathrm{H} \cdots A$ & $D-\mathrm{H}$ & $\mathrm{H} \cdots A$ & $D \cdots A$ & $D-\mathrm{H} \cdots A$ \\
\hline $\mathrm{N} 1-\mathrm{H} 1 \ldots \mathrm{O} 2^{i}$ & $0.82(2)$ & $1.908(16)$ & $2.6927(16)$ & $160.7(15)$ \\
\hline $\mathrm{N} 2-\mathrm{H} 21 \cdots \mathrm{O} 7^{i i}$ & $0.87(2)$ & $2.432(18)$ & $3.0104(19)$ & $124.3(14)$ \\
\hline $\mathrm{N} 2-\mathrm{H} 22 \cdots \mathrm{O} 2^{i}$ & $0.87(2)$ & $2.091(19)$ & $2.8871(19)$ & $151.6(16)$ \\
\hline $\mathrm{N} 4-\mathrm{H} 41 \cdots \mathrm{O} 2$ & $0.82(2)$ & $1.981(18)$ & $2.7977(18)$ & $178.8(17)$ \\
\hline $\mathrm{N} 4-\mathrm{H} 42 \cdots \mathrm{O} 1^{i i i}$ & $0.90(2)$ & $1.951(17)$ & $2.7943(17)$ & $154.9(15)$ \\
\hline 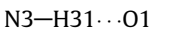 & $0.87(2)$ & $1.908(18)$ & $2.7745(18)$ & $171.7(15)$ \\
\hline N3-H32 ..S 1 & $0.82(2)$ & 2.319 (17) & 3.0074 (15) & $142.0(15)$ \\
\hline $\mathrm{O} 7-\mathrm{H} 7 \cdots \mathrm{S} 1^{i v}$ & $0.84(2)$ & $2.49(2)$ & $3.3072(13)$ & $162.7(19)$ \\
\hline \multicolumn{5}{|c|}{ 1-(Diaminomethylene) thiouron-1-ium 3,4-dihydroxybenzoate $(\mathbf{2})^{\mathrm{b}}$} \\
\hline$D-\mathrm{H} \cdots A$ & $D-\mathrm{H}$ & $\mathrm{H} \cdots A$ & $D \cdots A$ & $D-\mathrm{H} \cdots A$ \\
\hline $\mathrm{N} 1-\mathrm{H} 1 \cdots \mathrm{O} 2^{i}$ & $0.87(2)$ & $1.85(2)$ & $2.7035(14)$ & $167(2)$ \\
\hline $\mathrm{N} 2-\mathrm{H} 21 \cdots \mathrm{O} 2^{i}$ & $0.86(2)$ & $2.22(2)$ & $2.9524(17)$ & $143(2)$ \\
\hline $\mathrm{N} 2-\mathrm{H} 22 \cdots 6^{i i}$ & $0.87(2)$ & $2.14(2)$ & $2.9672(15)$ & $161(2)$ \\
\hline $\mathrm{N} 4-\mathrm{H} 41 \ldots \mathrm{O} 2$ & $0.89(2)$ & $2.00(2)$ & $2.8865(15)$ & $177(2)$ \\
\hline $\mathrm{N} 4-\mathrm{H} 42 \cdots \mathrm{O} 1^{i i i}$ & $0.90(2)$ & $1.98(2)$ & $2.7995(15)$ & $150(2)$ \\
\hline N3-H31 ‥ 01 & $0.91(2)$ & $2.00(2)$ & $2.9021(15)$ & $177(2)$ \\
\hline N3-H32 . S 1 & $0.83(2)$ & $2.42(2)$ & $3.0975(13)$ & $140(2)$ \\
\hline $\mathrm{O} 6-\mathrm{H} 6 \cdots \mathrm{O} 7^{i v}$ & $0.85(2)$ & $2.04(2)$ & $2.8534(15)$ & $159(2)$ \\
\hline $\mathrm{O} 7-\mathrm{H} 7 \ldots \mathrm{O} 6$ & $0.82(2)$ & $2.36(2)$ & $2.7918(15)$ & $113(2)$ \\
\hline $\mathrm{O} 7-\mathrm{H} 7 \ldots \mathrm{S} 1^{v}$ & $0.82(2)$ & $2.55(2)$ & $3.2339(12)$ & $141(2)$ \\
\hline \multicolumn{5}{|c|}{ 1-(Diaminomethylene) thiouron-1-ium 3,4,5-trihydroxybenzoate $(3)^{\mathrm{c}}$} \\
\hline$D-\mathrm{H} \cdots A$ & $D-\mathrm{H}$ & $\mathrm{H} \cdots A$ & $D \cdots A$ & $D-\mathrm{H} \cdots A$ \\
\hline $\mathrm{N} 1-\mathrm{H} 1 \cdots \mathrm{O} 1$ & $0.84(2)$ & $1.85(2)$ & $2.685(2)$ & $172(2)$ \\
\hline $\mathrm{N} 2-\mathrm{H} 22 \cdots \mathrm{O} 6^{i}$ & $0.79(2)$ & $2.19(2)$ & $2.910(2)$ & $152(2)$ \\
\hline $\mathrm{N} 2-\mathrm{H} 21 \cdots \mathrm{O} 2$ & $0.91(2)$ & $1.92(2)$ & $2.817(2)$ & $171(2)$ \\
\hline $\mathrm{N} 3-\mathrm{H} 32 \cdots \mathrm{S} 1$ & $0.89(2)$ & $2.26(2)$ & $2.989(2)$ & $140(2)$ \\
\hline $\mathrm{N} 3-\mathrm{H} 31 \cdots \mathrm{O} 3^{i i}$ & $0.83(2)$ & $2.38(2)$ & $2.960(2)$ & $127(2)$ \\
\hline $\mathrm{N} 3-\mathrm{H} 31 \cdots \mathrm{S} 1^{i i i}$ & $0.83(2)$ & $2.73(2)$ & $3.489(2)$ & $152(2)$ \\
\hline $\mathrm{N} 4-\mathrm{H} 42 \ldots \mathrm{O}^{i v}$ & $0.85(2)$ & $2.15(2)$ & $2.922(2)$ & $151(2)$ \\
\hline $\mathrm{N} 4-\mathrm{H} 41 \cdots \mathrm{S} 1^{i i i}$ & $0.89(2)$ & $2.54(2)$ & $3.356(2)$ & $153(2)$ \\
\hline $\mathrm{O} 6-\mathrm{H} 6 \cdots \mathrm{O} 7$ & $0.76(2)$ & $2.27(2)$ & $2.676(2)$ & $115(2)$ \\
\hline $\mathrm{O} 6-\mathrm{H} 6 \cdots \mathrm{S} 1^{v}$ & $0.76(2)$ & $2.74(2)$ & $3.401(2)$ & $148(2)$ \\
\hline $\mathrm{O} 7-\mathrm{H} 7 \cdots \mathrm{O}^{v i}$ & $0.85(2)$ & $1.91(2)$ & $2.688(2)$ & $151(2)$ \\
\hline $\mathrm{O} 8-\mathrm{H} 8 \cdots \mathrm{O} 2^{v i i}$ & $0.83(2)$ & $1.85(2)$ & $2.670(2)$ & $173(2)$ \\
\hline $\mathrm{O} 3-\mathrm{H} 13 \cdots \mathrm{O} 1^{\text {viii }}$ & $0.80(2)$ & $2.03(2)$ & $2.817(2)$ & $168(2)$ \\
\hline $\mathrm{O} 3-\mathrm{H} 14 \cdots \mathrm{O} 2$ & $0.80(2)$ & $2.39(2)$ & $3.147(2)$ & $159(2)$ \\
\hline
\end{tabular}

a Symmetry codes: (i) $-x, y+1 / 2,-z-1 / 2$; (ii) $x-1,-y+3 / 2, z-1 / 2$; (iii) $x$, $-y+3 / 2, z-1 / 2 ;(i v) x+1, y-1, z$.

b Symmetry codes: (i) $-x+1, y+1 / 2,-z+1 / 2$; (ii) $x+1, y+1, z$; (iii) $x,-y+1 / 2$, $z-1 / 2 ;(i v) x,-y-1 / 2, z-1 / 2 ;(v) x-1, y-1, z$

c Symmetry codes: (i) $-x+1, y-1 / 2,-z+1 / 2$; (ii) $-x, y-1 / 2,-z+1 / 2$; (iii) $x$, $-y+1 / 2, z+1 / 2$; (iv) $-x+1, y-1 / 2,-z+3 / 2$; (v) $x+1,-y+3 / 2, z+1 / 2$; (vi) $-x+1$, $-y+2,-z+1$; (vii) $x,-y+3 / 2, z+1 / 2$; (viii) $x,-y+3 / 2, z-1 / 2$.

shorter than the value of $\sim 1.74 \AA$ as observed in several thiolate anions that represents $50 \%$ double-bond character [21]. Thus the bond order of the $\mathrm{C} 1-\mathrm{S} 1$ bond is intermediate between the 2 and 1.5. The three $\mathrm{C}-\mathrm{N}$ bonds linking the amine groups are shorter than the $\mathrm{C}-\mathrm{N}$ bonds involving the central $\mathrm{N} 1$ atom (Table 2). These $\mathrm{C}-\mathrm{N}$ bonds linking the amine groups, except the $\mathrm{C} 1-\mathrm{N} 2$ in the crystal 2 , are slightly shorter than the typical single bond $\mathrm{C}\left(\mathrm{sp}^{2}\right)$ $-\mathrm{NH}_{2}$ of $1.341-1.363 \AA$ [22]. The planarity of the amine groups points to the $\mathrm{sp}^{2}$ hybridisation of the orbitals on the amine nitrogen atoms. Therefore the partial delocalisation of $\pi$ bonds of the double $\mathrm{C} 1=\mathrm{S} 1$ and $\mathrm{C} 2=\mathrm{N} 1$ bonds is possible and leads to shortening of other $\mathrm{C}-\mathrm{N}$ bonds linking the amine groups and to the elongation of the $\mathrm{C} 1=\mathrm{S} 1$ and $\mathrm{C} 2=\mathrm{N} 1$ bonds (Table 2 ). Thus the bond order of the $\mathrm{C}-\mathrm{NH}_{2}$ bonds is greater than of the both $\mathrm{C}-\mathrm{N}$ bonds involving the central $\mathrm{N} 1$ atom.

The 1-(diaminomethylene)thiouron-1-ium cation contains the sulphur atom that can form hydrogen bonds as an acceptor, although the importance of such interactions has been questioned [23]. However, the D-H $\cdots$ S interactions ( $D=$ donor) are important in the biological systems due to presence of high content of $S$ atom in biological molecules. In addition, the $\mathrm{N}-\mathrm{H} \ldots \mathrm{S}$ interactions have been utilised for design supramolecular arrangement of thiourea derivatives [24]. Therefore, such $\mathrm{N}-\mathrm{H} \ldots \mathrm{S}$ intramolecular 
(a)

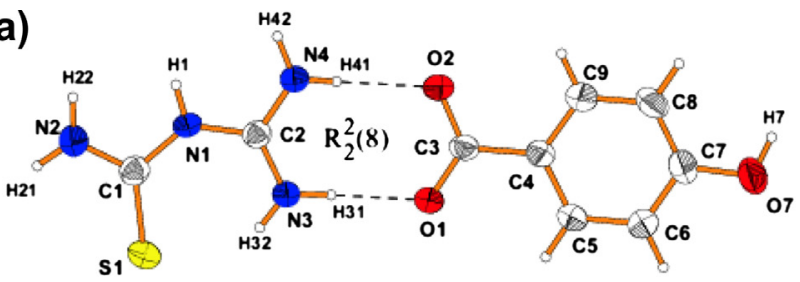

(b)
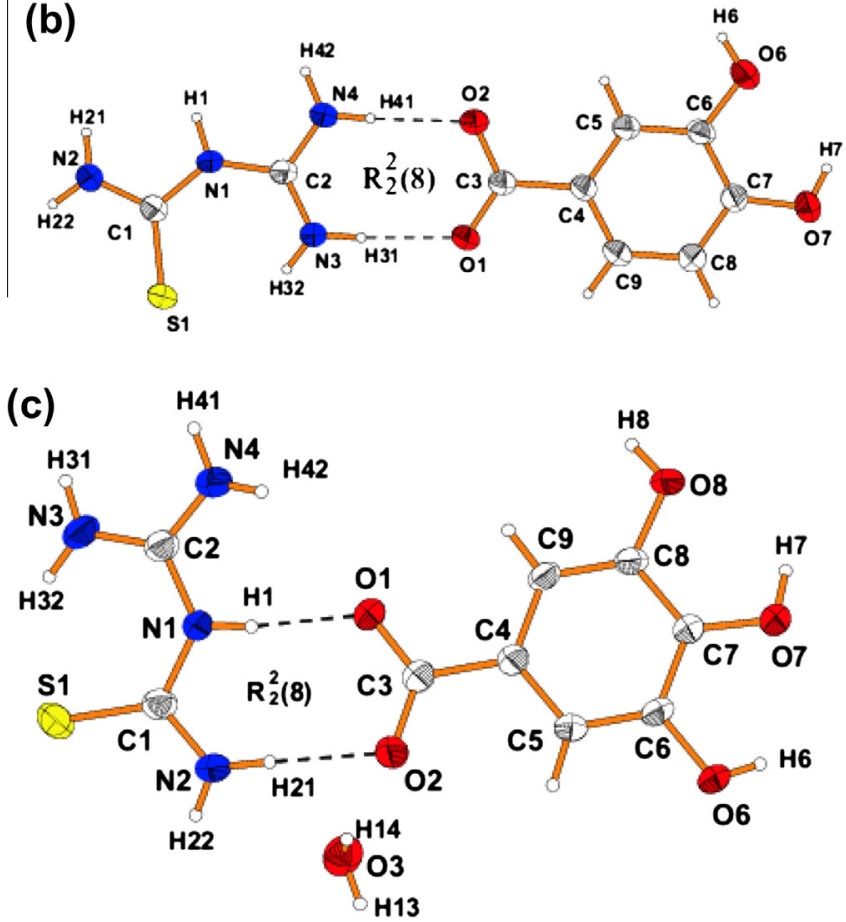

Fig. 1. A view of 1-(diaminomethylene)thiouron-1-ium 4-hydroxybenzoate (a), 1-(diaminomethylene)thiouron-1-ium 3,4-dihydroxybenzoate (b) and 1-(diaminomethylene)thiouron-1-ium 3,4,5-trihydroxybenzoate monohydrate (c) showing displacement ellipsoids at the $50 \%$ probability level and $\mathrm{H}$ atoms as a sphere of arbitrary radii. Dashed lines represent the hydrogen bonds.

interactions seem to be important in the present structures (Table 3), where the formation of the intramolecular $\mathrm{N}-\mathrm{H} \ldots \mathrm{S}$ interactions is favoured by the six-membered hydrogen-bonded ring with a graph of $S(6)$; the presence of $C=S$ bond makes it some resonance-assisted stabilisation. The possibility of resonance-induced hydrogen bond ring formation with the $S$ atom of a $C=S$ group with $\mathrm{N}$ substituents has been mentioned by Allen et al. [25]. Besides the $\mathrm{N}-\mathrm{H} \cdots \mathrm{S}$ intramolecular interactions, the $\mathrm{N}-\mathrm{H} \cdots \mathrm{S}$ intermolecular interactions in the present structures also exist. However, in these structures the hydrogen bonds involving the $\mathrm{S}$ atom seem to be driven by the stronger $\mathrm{N}-\mathrm{H} \cdots \mathrm{O}$ and $\mathrm{O}-\mathrm{H} \cdots \mathrm{O}$ hydrogen bonds. In addition, the weak hydrogen bonds of $\mathrm{O}-\mathrm{H} \ldots \mathrm{S}$ between the hydroxyl group at para-position in relation to carboxylate group are present in these structures (Table 3 ).

The geometrical parameters of the anionic parts of the crystals, i.e. 4-hydroxybenzoate, 3,4-dihydroxybenzoate and 3,4,5-trihydroxybenzoate, do not deviate significantly from the reported values in the other structures containing these anions [26]. The $\mathrm{C}-\mathrm{O}$ bond lengths of the $\mathrm{COO}^{-}$groups point on delocalisation of the $\pi$-bond and the charge over both $\mathrm{C}-\mathrm{O}$ bonds. The $\mathrm{COO}^{-}$group is slightly inclined to the benzene ring. The dihedral angle between the planes of $\mathrm{COO}^{-}$and benzene ring is equal to $6.2(2), 2.0(2)$ and $5.1(2)^{\circ}$ in the crystals $\mathbf{1}, \mathbf{2}$ and $\mathbf{3}$, respectively. For comparison, in the crystal of 4-hydroxybenzoic acid the $\mathrm{COOH}$ group is also slightly inclined $\left(\sim 3.1(2)^{\circ}\right)$ to the benzene ring [27]. In the crystal
Table 4

The dihedral angle between the arms of the 1-(diaminomethylene)thiouron-1-ium cation in the known salts.

\begin{tabular}{|c|c|c|}
\hline Compounds & $\begin{array}{l}\text { Angle } \\
\left({ }^{\circ}\right)\end{array}$ & Reference \\
\hline 1-(Diaminomethylene)thiourea, in the crystal & $22.2(1)$ & {$[1]$} \\
\hline 1-(Diaminomethylene)thiouron-1-ium chloride & $22.9(1)$ & [5] \\
\hline 1-(Diaminomethylene)thiouron-1-ium bromide & $15.2(1)$ & [5] \\
\hline 1-(Diaminomethylene)thiouron-1-ium iodide & $4.2(1)$ & [5] \\
\hline 1-(Diaminomethylene)thiourea, $a b$ initio calculations & 6.2 & [6] \\
\hline 1-(Diaminomethylene)thiouron-1-ium chlorate(VII) & $1.4(1)$ & {$[6]$} \\
\hline $\begin{array}{l}\text { 1-(Diaminomethylene)thiouron-1-ium hydrogen } \\
\text { sulphate }\end{array}$ & $9.8(1)$ & [6] \\
\hline $\begin{array}{l}\text { 1-(Diaminomethylene)thiouron-1-ium dihydrogen } \\
\text { phosphonate }\end{array}$ & $4.4(1)$ & {$[6]$} \\
\hline $\begin{array}{l}\text { 1-(Diaminomethylene)thiouron-1-ium dihydrogen } \\
\text { arsenate }\end{array}$ & 2.1(1) & {$[6]$} \\
\hline 1-(Diaminomethylene)thiouron-1-ium nitrate & $7.2(1)$ & [7] \\
\hline $\begin{array}{l}\text { 1-(Diaminomethylene)thiouron-1-ium phosphonate } \\
\text { monohydrate }\end{array}$ & $3.7(1)$ & [7] \\
\hline 1-(Diaminomethylene)thiouron-1-ium formate & $5.5(2)$ & {$[10]$} \\
\hline $\begin{array}{l}\text { Bis[1-(diaminomethylene)thiouron-1-ium] oxalate } \\
\text { dihydrate }\end{array}$ & $4.5(2)$ & [10] \\
\hline 1-(Diaminomethylene)thiouron-1-ium picrate & $1.3(1)$ & {$[11]$} \\
\hline Bis[1-(diaminomethylene)thiouron-1-ium] fumarate & $13.8(1)$ & {$[12]$} \\
\hline Bis[1-(diaminomethylene)thiouron-1-ium] oxalate & $5.0(1)$ & [13] \\
\hline $\begin{array}{l}\text { 1-(Diaminomethylene)thiouron-1-ium 4- } \\
\text { hydroxybenzoate }\end{array}$ & $2.0(2)$ & This work \\
\hline $\begin{array}{l}\text { 1-(Diaminomethylene)thiouron-1-ium 3,4- } \\
\text { dihydroxybenzoate }\end{array}$ & $5.1(2)$ & This work \\
\hline $\begin{array}{l}\text { 1-(Diaminomethylene)thiouron-1-ium 3,4,5- } \\
\text { trihydroxybenzoate monohydrate }\end{array}$ & $6.2(2)$ & This work \\
\hline
\end{tabular}

of 3,4-dihydroxybenzoic acid (anhydrous) the $\mathrm{COOH}$ group is coplanar with the benzene ring [28], while in the crystal of 3,4dihydroxybenzoic acid monohydrate the $\mathrm{COOH}$ is rotated by $\sim 31^{\circ}$ in relation to benzene ring around the $\mathrm{C}-\mathrm{C}$ bond [29]. In anhydrous crystal of 3,4,5-trihydroxybenzoic acid the $\mathrm{COOH}$ group is coplanar with the ring [30,31] whereas in the crystal of 3,4,5-trihydroxybenzoic acid monohydrate the $\mathrm{COOH}$ group is slightly inclined to the ring $\left(\sim 3.2(2)^{\circ}\right)$ [32].

The oppositely charged units in these crystals interact via a pair of almost linear $\mathrm{N}-\mathrm{H} \cdots \mathrm{O}$ hydrogen bonds with a graph $\mathrm{R}_{2}{ }^{2}(8)$ forming hydrogen bonded cation-anion complex. The hydrogen bonding patterns involving the carboxylate groups are quite similar in crystal $\mathbf{1}$ and 2, but different in crystal 3. In $\mathbf{1}$ and $\mathbf{2}$, the $\mathrm{R}_{2}{ }^{2}(8)$ motif is formed by donation to the $\mathrm{COO}^{-}$group of anions from the amino groups bonded to the $\mathrm{C} 2$ atom (Fig. $1 \mathrm{a}$ and $\mathrm{b}$, Table 3 ), whereas in the crystal 3 the $\mathrm{R}_{2}^{2}(8)$ motif is created via participation of the iminium group (N1) and amine group (N2) bonded to $\mathrm{C} 1$ atom of the cation as a donors and the $\mathrm{O} 1$ and $\mathrm{O} 2$ atoms of carboxylate group of the anion as acceptors (Fig. 1c). It is interesting that the $R_{2}{ }^{1}(6)$ motif present in the crystals 1 and $\mathbf{2}$ (Fig. 2a and b), involving two hydrogen bonds with the central $\mathrm{N} 1$ atom and the $\mathrm{N} 2$ amino group of the cation as donors and the carboxylate $\mathrm{O} 2$ atom of the anion as acceptor, in the crystal 3 the $R_{2}{ }^{1}(6)$ motif is not present. In the crystal 1 three extended hydrogen bonding motifs, $\mathrm{R}_{4}{ }^{4}(16), \mathrm{R}_{4}{ }^{4}(20)$ and $\mathrm{R}_{4}{ }^{4}(24)$, linking two pairs of cations and anions into centrosymmetric 2:2 supramolecular complexes are observed (Fig 2a). In the crystal 2, the two extended hydrogen bonding motifs of $\mathrm{R}_{4}^{4}(16)$ and $\mathrm{R}_{4}^{4}(20)$ forming centrosymmetric 2:2 supramolecular complexes are present (Fig $2 \mathrm{~b}$ ). In the crystal structure of 3 the another hydrogen bonding motifs of $\mathrm{D}_{3}{ }^{3}(14)$, $\mathrm{D}_{3}{ }^{3}(16), \mathrm{R}_{4}{ }^{4}(22)$ and $\mathrm{R}_{6}{ }^{6}(20)$ can be found (Fig. 2c).

The crystal packing diagram of $\mathbf{1}$ is illustrated in Fig. 3a and b. The almost planar $\mathrm{R}_{2}{ }^{2}(8)$ hydrogen bonded cation-anion complexes are alternatively located parallel and perpendicular to the (110) crystallographic plane. These cation-anion complexes are cross-linked via $\mathrm{N}-\mathrm{H} \ldots \mathrm{O}$ hydrogen bond involving the $\mathrm{N} 2$ amine 
(a)

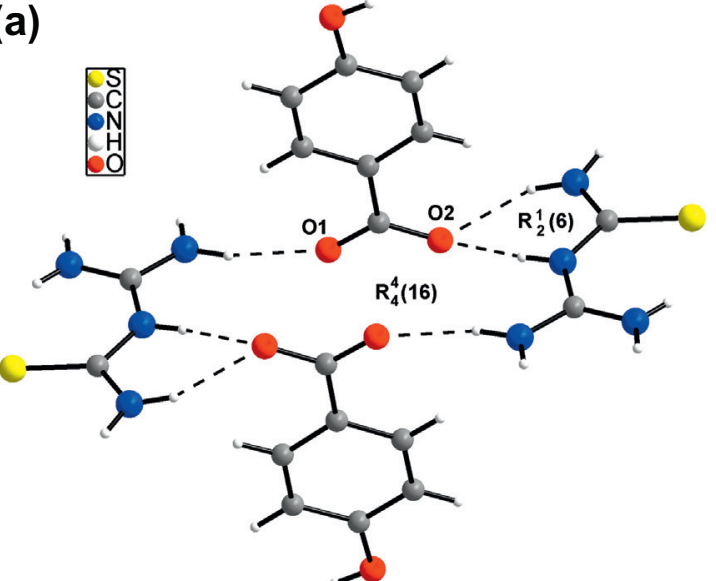

(1)

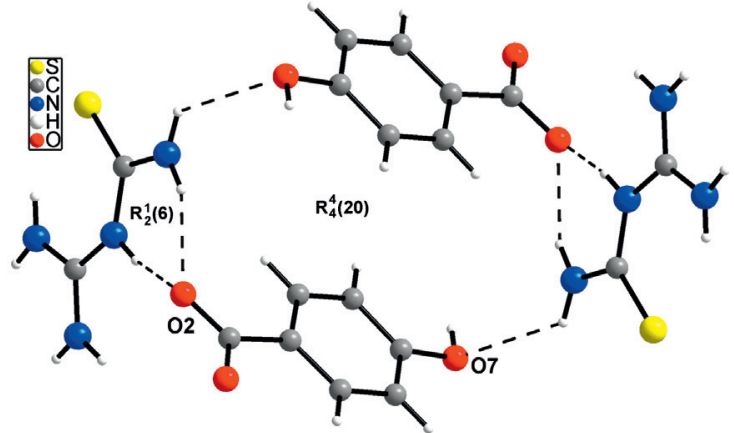

(2)

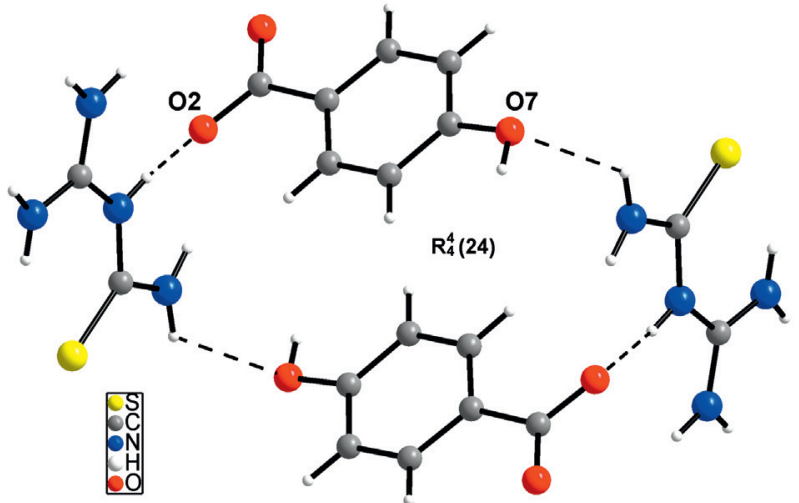

(3)

(b)
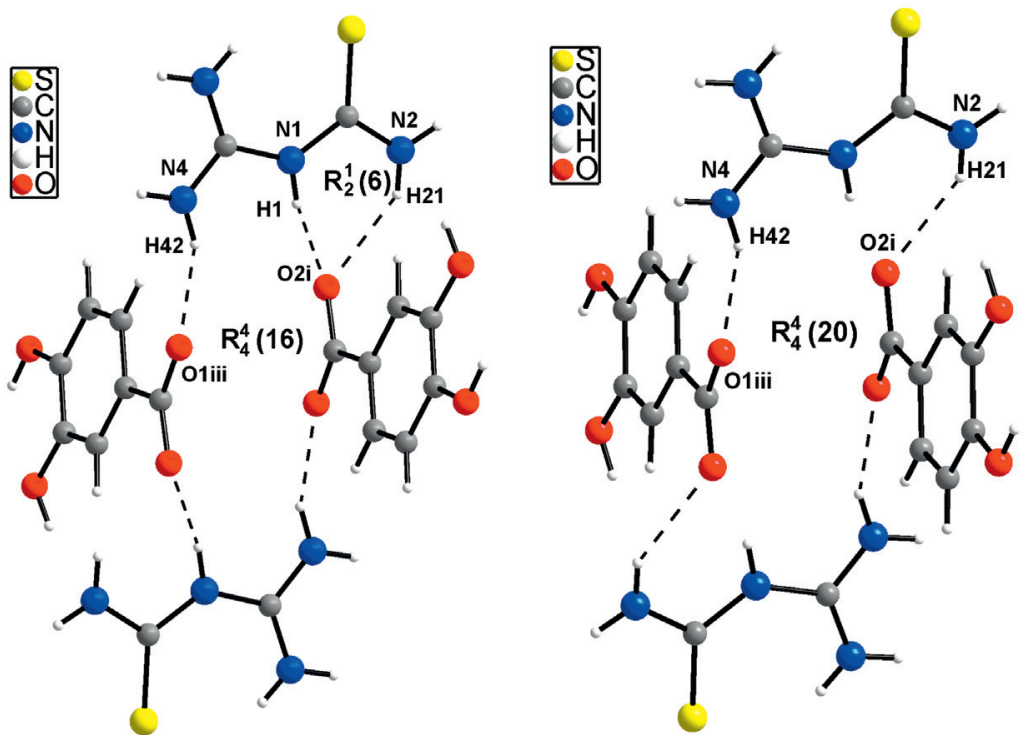

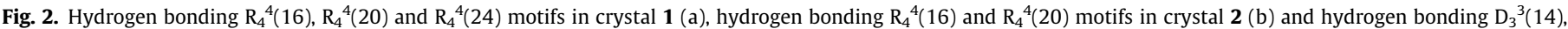
$\mathrm{D}_{3}{ }^{3}(16), \mathrm{R}_{4}{ }^{4}(22)$ and $\mathrm{R}_{6}{ }^{6}(20)$ motifs in crystal 3 (c).

as a donor of the cation and hydroxyl group (07) of the anion as well as via $\mathrm{N}-\mathrm{H} \ldots \mathrm{O}$ hydrogen bonds between the $\mathrm{O} 1$ atom as acceptor and N3 amine group as donor and $\mathrm{O} 2$ and iminium N1 atom and $\mathrm{N} 2$ amine group as donors forming three dimensional hydrogen bonding network (Table 3a and Fig. 3).
The arrangement of the $\mathrm{R}_{2}{ }^{2}(8)$ hydrogen bonded cation-anion complexes in the crystal $\mathbf{2}$ forming three dimensional hydrogen bonding network, in general, is similar to that in crystal $\mathbf{1}$ (Fig. 4). However, in the crystal 2 the hydroxyl group attached to $\mathrm{C} 6$ atom of the anion that forms intramolecular $07-\mathrm{H} 7 \ldots 06$ and 
(c)

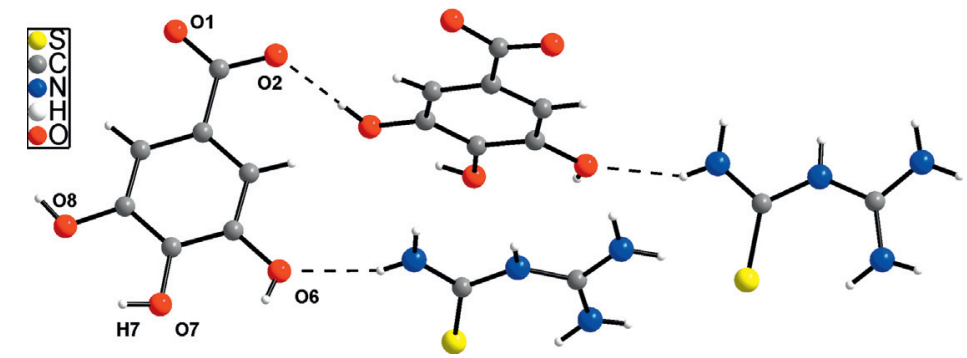

$\mathrm{D}_{3}^{3}(14)$

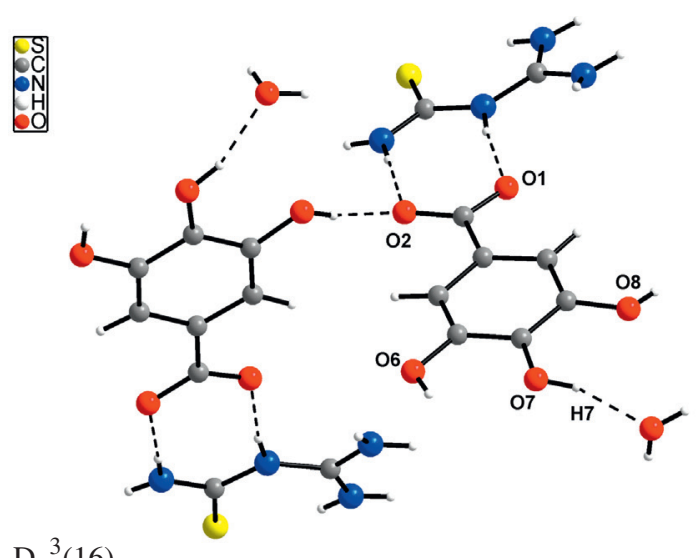

$\mathrm{D}_{3}{ }^{3}(16)$

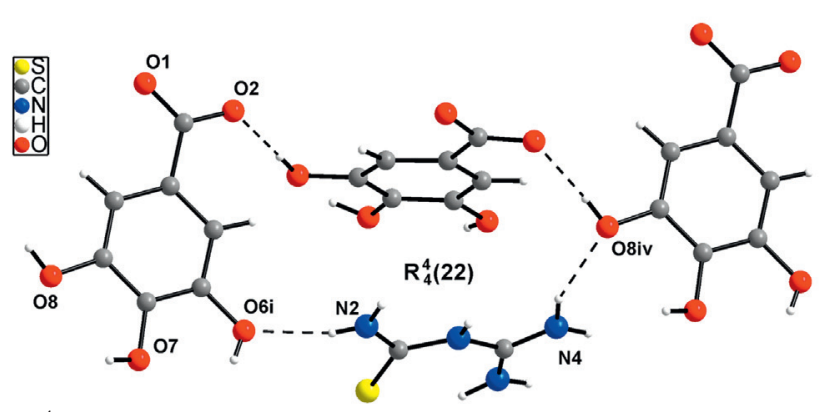

$\mathrm{R}_{4}{ }^{4}(22)$

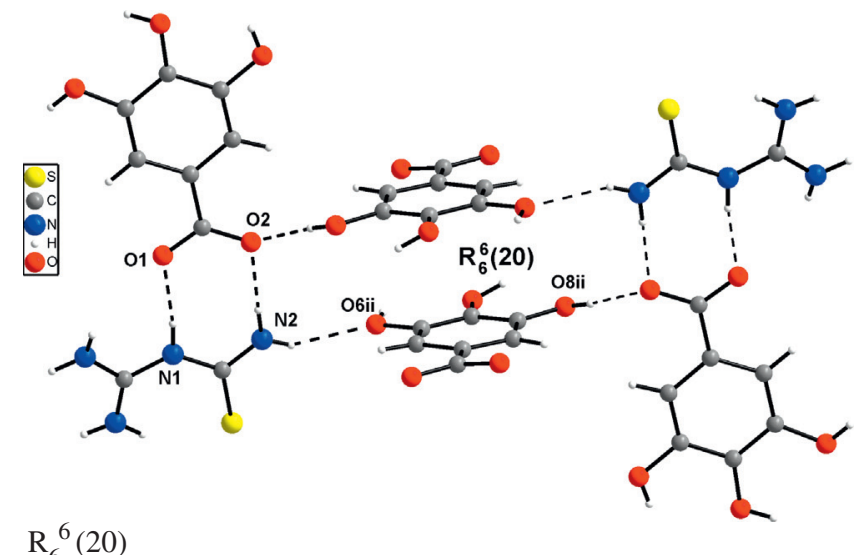

Fig. 2. (continued)

intermolecular $\mathrm{O} 6-\mathrm{H} 6 \cdots \mathrm{O} 7^{\text {iv }}$ hydrogen bonds (Table $3 \mathrm{~b}$ ) is responsible for the slightly difference between the hydrogen bonding networks in $\mathbf{1}$ and in $\mathbf{2}$.
The crystal packing diagram of $\mathbf{3}$ forming three-dimensional hydrogen bonding network (Fig. 5) is different than that in the crystals $\mathbf{1}$ and $\mathbf{2}$. As can be seen from the Fig. 5, the 

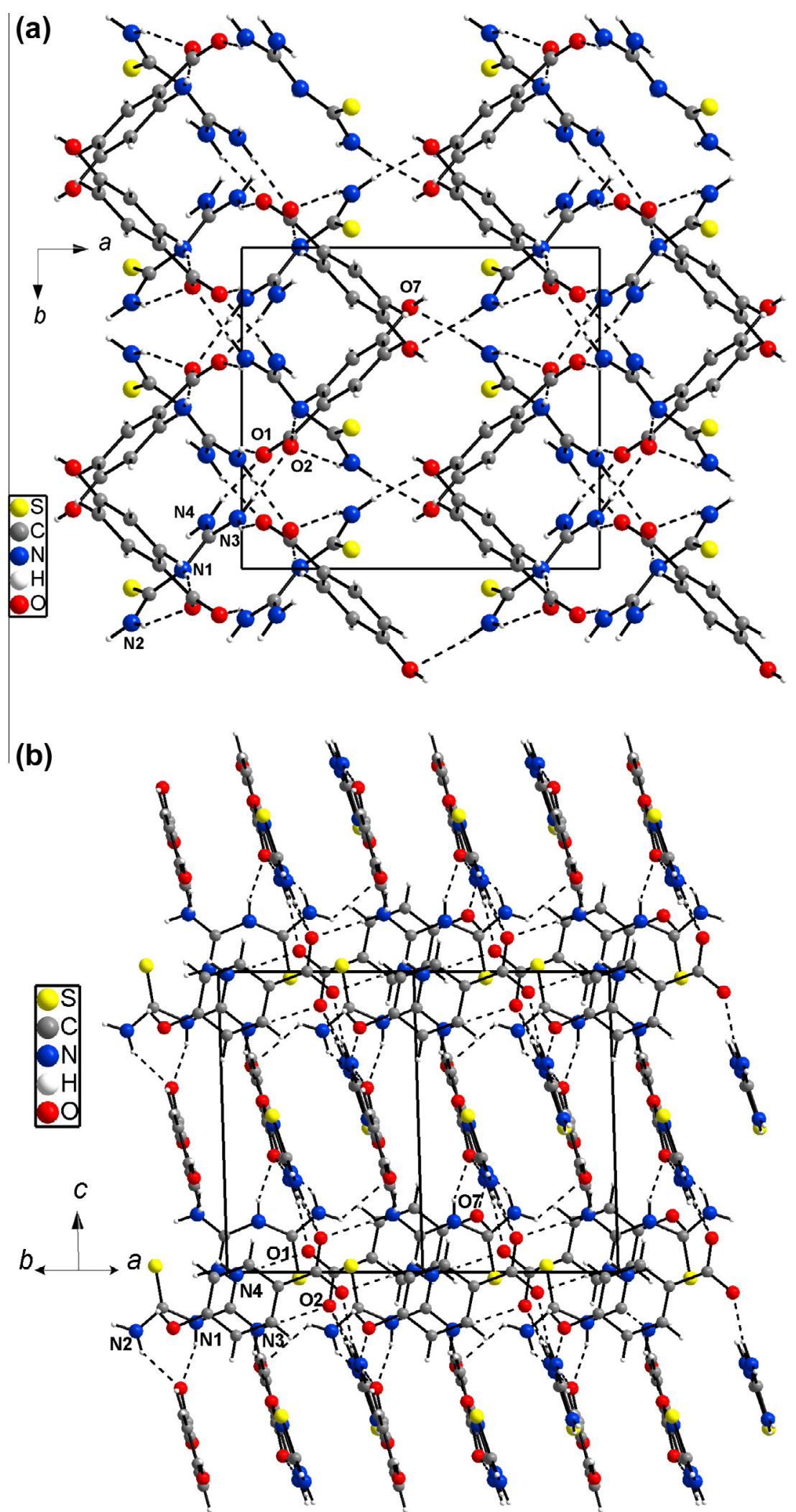

Fig. 3. View along $c$-axis (a) and (110) direction (b) of the crystal packing of 1-(diaminomethylene) thiouron-1-ium 4-hydroxybenzoate (1).

O-H $\cdots$ O hydrogen bonded substructure of the 3,4,5-trihydroxybenzoate anions and water molecules forming pseudo twodimensional layer extending parallel to the (100) plane is present (Fig. 5b). The water molecule acts as a donor and as an acceptor in the four hydrogen bonds (Table 3c). The neighbouring pseudo two-dimensional layers are interconnected by the 1-(diaminomethylene)thiouron-1-ium cations via $\mathrm{N}-\mathrm{H} \cdots \mathrm{O}$ hydrogen bonds forming three-dimensional hydrogen bonded 

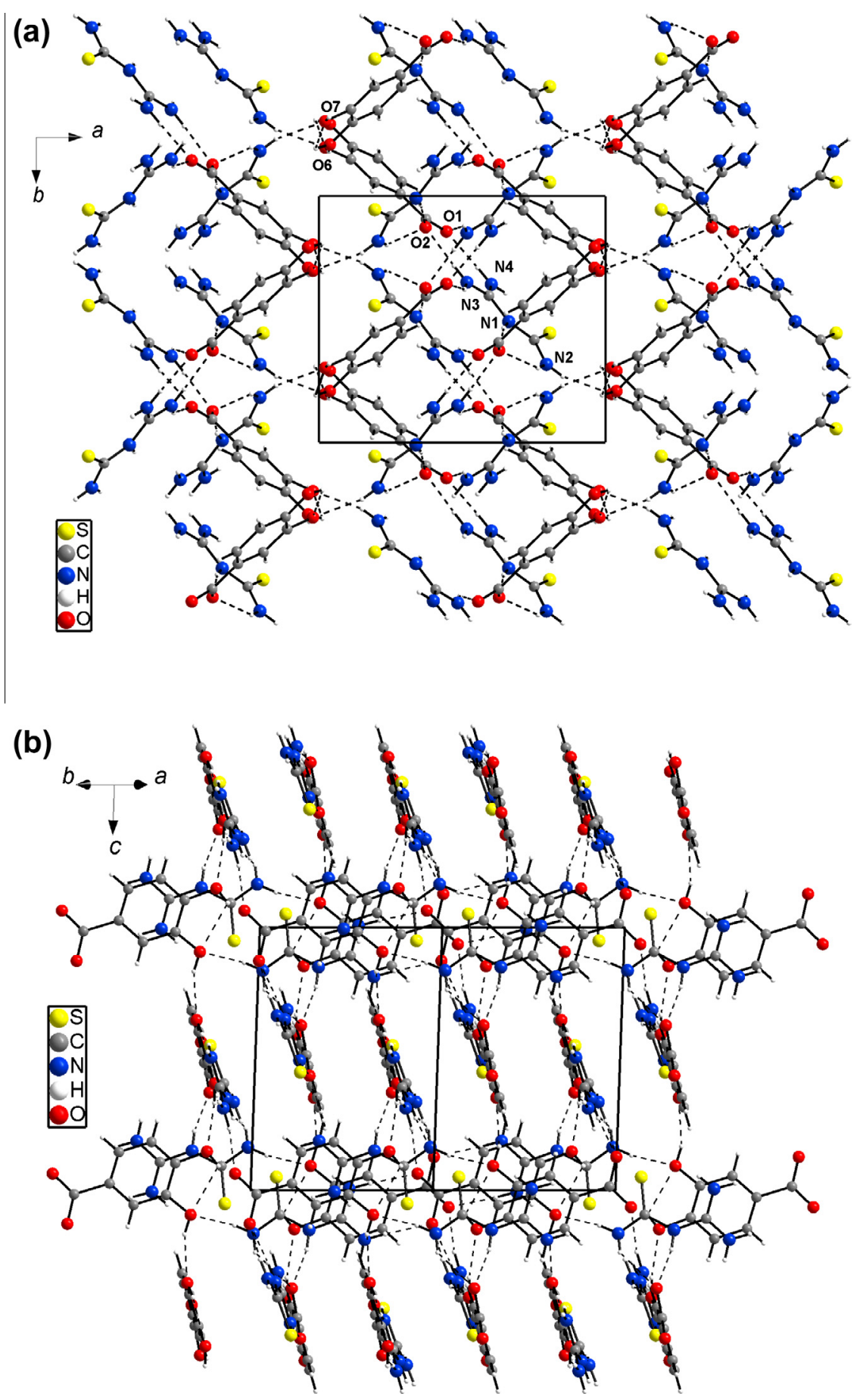

Fig. 4. View along c-axis (a) and (110) direction (b) of the crystal packing of 1-(diaminomethylene) thiouron-1-ium 3,4-hydroxybenzoate (2),

network (Fig. 5a). The benzene rings of neighbouring 3,4,5-trihydroxybenzoate anions are separated by 3.514(3) A. This value indicates the presence of the $\pi-\pi$ interactions between the aromatic rings [33]. The $\pi-\pi$ interactions between the neighbouring benzene rings of 4-hydroxybenzoate or 3,4-dihydroxybenzoate anions in crystal $\mathbf{1}$ or $\mathbf{2}$ are not observed, since they are slipped. The hydrogen bonds involving water molecule and the $\pi-\pi$ interactions lead to more compact arrangement of neighbouring aromatic benzoate anions in the structure $\mathbf{3}$ comparing to that in the structure $\mathbf{1}$ and $\mathbf{2}$, as well as to greater density of $\mathbf{3}$ $\left(1.59 \mathrm{~g} / \mathrm{cm}^{3}\right)$ when compared with that of $\mathbf{1}$ and 2 (1.49 and $1.43 \mathrm{~g} / \mathrm{cm}^{3}$, respectively).
The FT-IR spectra of 1-(diaminomethylene)thiouron-1-ium 4hydroxybezoate, 1-(diaminomethylene)thiouron-1-ium 3,4dihydroxybenzoate and 1-(diaminomethylene)-thiouron-1-ium 3,4,5-trihydroxybenzoate monohydrate are shown in Fig. 6a, b and $\mathrm{c}$, respectively. Investigated here compounds have several functional and skeletal groups such as the three $\mathrm{NH}_{2}, \mathrm{C}=\mathrm{S}, \mathrm{C}-\mathrm{N}-\mathrm{C}$, $\mathrm{N}-\mathrm{C}-\mathrm{N}$ and $\mathrm{N}-\mathrm{C}-\mathrm{S}$ groups in the cation and $\mathrm{COO}^{-}$, one, two or three $\mathrm{OH}$ groups, $\mathrm{C}-\mathrm{H}$ and benzene ring in the anions. The bands corresponding to the vibration of the functional groups were identified with the aid of infrared correlation chart [34,35]. In addition, the spectra of these compounds are compared with the spectrum of 1-(diaminomethylene)thiourea [11]. A careful inspection of the 

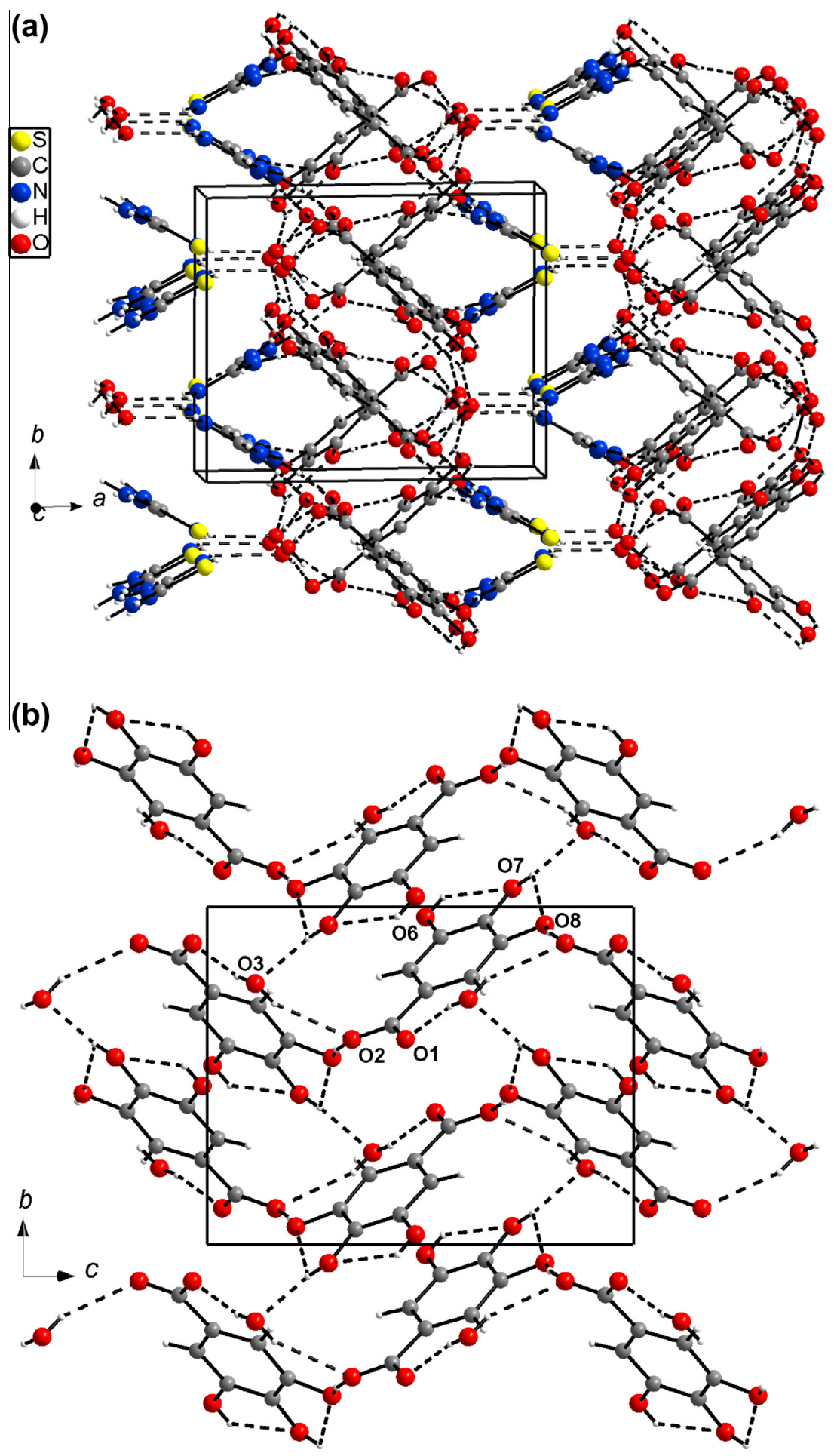

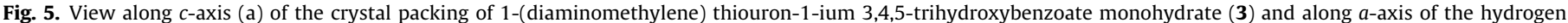
bonded substructure of 3,4,5-trihydroxybenzoate anions and water molecules (b).

IR-spectra (Fig. 6a-c) shows a narrow band at above $3400 \mathrm{~cm}^{-1}$ assigned to the vibration of the hydroxyl group of the respective anion. In the crystal $\mathbf{1}$ the $\mathrm{OH}$ group is only involved in a weak $\mathrm{O}-\mathrm{H} \cdots \mathrm{S}$ hydrogen bond, so the $v(\mathrm{OH})$ appear at higher wavenumber $\left(3479 \mathrm{~cm}^{-1}\right)$ than in the crystals 2 and $\mathbf{3}$, in which the hydroxyl groups are involved into a medium intra- and intermolecular $\mathrm{O}-\mathrm{H} \cdots \mathrm{O}$ hydrogen bonds with $\mathrm{O} \cdots \mathrm{O}$ distances of $2.7918(15)$ and 2.8534(15) $\AA$ in 2 and 2.676(2), 2.688(2) and 2.670(2) $\AA$ in 3, and the respective $v(\mathrm{OH})$ are observed at $3437 \mathrm{~cm}^{-1}$ and $3429 \mathrm{~cm}^{-1}$, respectively. Thus the wavenumber of $v(\mathrm{OH})$ correlates well with the strength of the $\mathrm{O}-\mathrm{H} \cdots \mathrm{O}$ interactions. The bands observed in the spectral region of $3400-3000 \mathrm{~cm}^{-1}$ are assigned to asymmetric and symmetric stretching of the three $\mathrm{NH}_{2}$ groups of 1-(diaminomethylene)thiouron-1-ium cation, at higher wavenumber appeared the $v_{\mathrm{a}}\left(\mathrm{NH}_{2}\right)$ while $v_{\mathrm{s}}\left(\mathrm{NH}_{2}\right)$ at lower. The origin of the relatively strong narrow band at $\sim 1722 \mathrm{~cm}^{-1}$, which is not observed in pure 1-(diaminomethylene)thiourea [11] could be ascribed to stretching of an iminium bond of 1-(diaminomethylene)thiouron-1-ium 

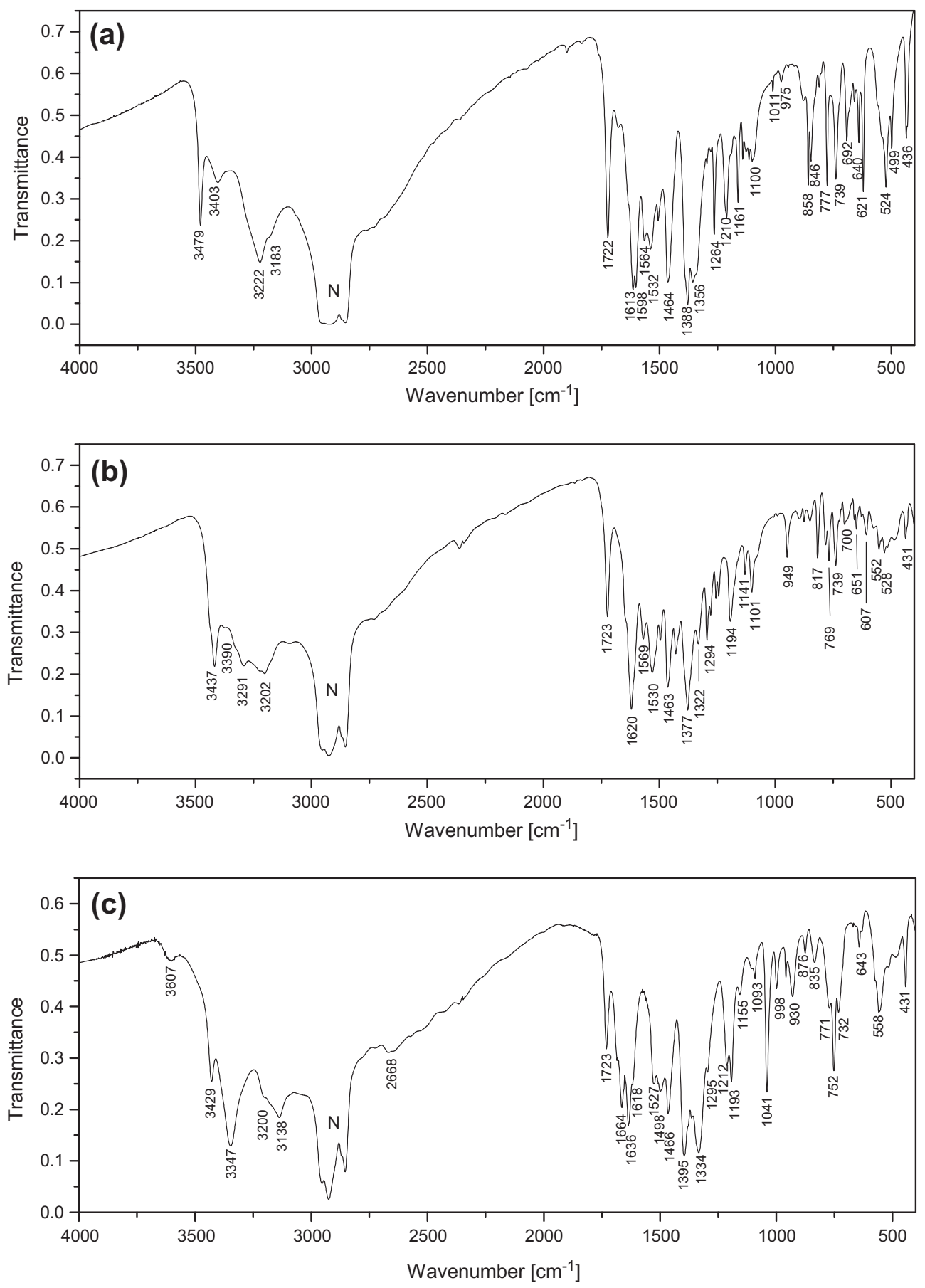

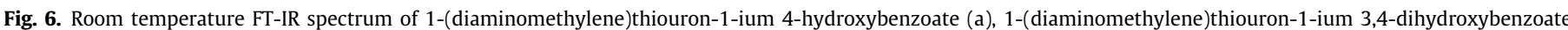
(b) and 1-(diaminomethylene)thiouron-1-ium 3,4,5-trihydroxybenzoate monohydrate (c).

cation, since a similar band is observed in some imines and their salts [36]. The X-ray data reveal that the $\mathrm{NH}_{2}$ groups of 1-(diaminomethylene)thiouron-1-ium cation are involved in the $\mathrm{N}-\mathrm{H} \cdots \mathrm{O}$ and the $\mathrm{N}-\mathrm{H} \ldots \mathrm{S}$ hydrogen bonds (Table 3 ). In the crystal 2 and 3 the hydroxyl groups of the respective anion are involved in $\mathrm{O}-\mathrm{H} \ldots \mathrm{O}$ hydrogen bonds with $\mathrm{O} \ldots \mathrm{O}$ distances of $2.670(2)-$ 3.147(2) $\AA$. This is reflected in the infrared spectrum as a broad band in the range of $3300-2500 \mathrm{~cm}^{-1}$. Additionally, the broad band in the range of $1500-1100 \mathrm{~cm}^{-1}$ overlapped with the $v(\mathrm{C}-\mathrm{C})_{\mathrm{arom}}$, $\delta\left(\mathrm{NH}_{2}\right)$ and $v(\mathrm{C}-\mathrm{N})$ of the cation and with $v_{\mathrm{s}}\left(\mathrm{COO}^{-}\right)$of the respective anion points to the $\mathrm{N}-\mathrm{H} \cdots \mathrm{O}$ hydrogen bonds. The bands at $\sim 1100 \mathrm{~cm}^{-1}$ can be attributed to the $\gamma\left(\mathrm{NH}_{2}\right)$ overlapped with
$v(\mathrm{C}-\mathrm{N})$ of the cation, which is also observed in the in pure 1-(diaminomethylene)thiourea [11]. The $v(C=S)$ band of the 1-(diaminomethylene)thiouron-1-ium cation, similar as in pure 1-(diaminomethylene)thiourea and in thiourea, is observed at $\sim 740-730 \mathrm{~cm}^{-1}$. In several thiourea metal complexes the $v(\mathrm{C}=\mathrm{S})$ band is observed at slightly lower wavenumber $\left(715-700 \mathrm{~cm}^{-1}\right)$ [37]. The anionic part of the crystals, 4-hydroxybezoate, 3,4dihydroxybenzoate and 3,4,5-trihydroxybenzoate anions, has characteristic strong narrow band of the hydroxyl group(s) at above $3400 \mathrm{~cm}^{-1}$ as mentioned above and the $v_{\mathrm{a}}$ and $v_{\mathrm{s}}$ of the carboxylate group and the bands of the $v(\mathrm{C}-\mathrm{C})_{\text {arom }}, v(\mathrm{C}-\mathrm{H})$ and the skeletal $\mathrm{C}-\mathrm{C}-\mathrm{C}$ groups (Table 5$)$. The $v_{\mathrm{a}}\left(\mathrm{COO}^{-}\right)$band is observed at higher 
Table 5

FT IR spectral data for 1-(diaminomethylene) thiouron-1-ium 4-hydroxybenzoate (1), 3,4-dihydroxybenzoate (2) and 3,4,5-trihydroxybenzoate monohydrate (3).

\begin{tabular}{|c|c|c|c|}
\hline $\begin{array}{l}\mathbf{1} / v \\
\left(\mathrm{~cm}^{-1}\right)\end{array}$ & $\begin{array}{l}\mathbf{2} / v \\
\left(\mathrm{~cm}^{-1}\right)\end{array}$ & $3 / v\left(\mathrm{~cm}^{-1}\right)$ & Assignment \\
\hline & & $\begin{array}{l}\text { 3607w and } \\
\sim 3510 \text { sh }\end{array}$ & $v_{\mathrm{a}}$ and $v_{\mathrm{s}}(\mathrm{OH}$ of water $)$ \\
\hline 3479s & $3437 s$ & $3429 \mathrm{~m}$ & $v(\mathrm{OH})$ of respective anion \\
\hline $3403 w$ & $3390 \mathrm{~m}$ & $3347 s$ & $\begin{array}{l}v_{\mathrm{a}} \text { and } v_{\mathrm{s}} \text { of the three } \mathrm{NH}_{2} \text { groups of } \\
\text { the cation }\end{array}$ \\
\hline $3222 s$ & $3291 \mathrm{~m}$ & $3200 \mathrm{~m}$ & \\
\hline $3183 \mathrm{~m}$ & $3202 \mathrm{~m}$ & $\begin{array}{l}3138 m \\
2668 w\end{array}$ & \\
\hline $1722 s$ & $1723 \mathrm{~s}$ & $1723 \mathrm{~m}$ & Imine bond stretch \\
\hline $1613 v s$ & $1620 v s$ & $1664 \mathrm{~s}$ & $v(\mathrm{C}-\mathrm{C})_{\mathrm{arom}}$ \\
\hline 1598vs & $1605 s$ & $\begin{array}{l}1638 v s \\
1618 s\end{array}$ & \\
\hline $1564 \mathrm{~m}$ & $1569 \mathrm{~m}$ & 1560 & $v_{\mathrm{a}}\left(\mathrm{COO}^{-}\right)$ \\
\hline $1532 \mathrm{~m}$ & $1530 \mathrm{~m}$ & $\begin{array}{l}1527 \mathrm{~m} \\
1498 \mathrm{~s}\end{array}$ & $v(\mathrm{C}-\mathrm{N})$ overlapped with $\delta\left(\mathrm{NH}_{2}\right)$ \\
\hline $1464 s$ & $1463 \mathrm{~s}$ & $1466 s$ & $v_{\mathrm{s}}\left(\mathrm{COO}^{-}\right)$ \\
\hline $1388 v s$ & $1386 \mathrm{~s}$ & 1395vs & $v(\mathrm{C}-\mathrm{N})$ \\
\hline $1378 s$ & $1377 \mathrm{~s}$ & $1377 s$ & $v(\mathrm{C}-\mathrm{N})$ \\
\hline $1356 s$ & $1355 \mathrm{~s}$ & $1355 s$ & $v(\mathrm{C}-\mathrm{C})_{\text {arom }}$ \\
\hline $1342 \mathrm{~s}$ & $1322 \mathrm{~s}$ & $1334 s$ & $\delta\left(\mathrm{NH}_{2}\right)$ \\
\hline $1292 \mathrm{~m}$ & $1294 \mathrm{~m}$ & $1295 \mathrm{~m}$ & $\delta\left(\mathrm{NH}_{2}\right)$ \\
\hline $1264 \mathrm{~m}$ & 1266w & & $v(\mathrm{C}-\mathrm{N})$ \\
\hline $1210 \mathrm{~m}$ & $1194 \mathrm{~m}$ & $1212 \mathrm{~m}$ & $v(\mathrm{C}-\mathrm{N})$ \\
\hline $1161 \mathrm{~m}$ & $1141 w$ & $1155 w$ & $v(\mathrm{C}-\mathrm{N})$ \\
\hline $1100 \mathrm{~m}$ & $1101 \mathrm{~m}$ & $1101 w$ & $\gamma\left(\mathrm{NH}_{2}\right)$ overlapped with $v(\mathrm{C}-\mathrm{N})$ \\
\hline 975w & $949 w$ & 1093w & $\beta(\mathrm{C}-\mathrm{H})$ \\
\hline $858 \mathrm{~m}$ & $817 w$ & $1041 \mathrm{~s}$ & $\gamma(\mathrm{C}-\mathrm{H})$ \\
\hline \multirow[t]{4}{*}{$846 \mathrm{~m}$} & & 998w & $\gamma(\mathrm{C}-\mathrm{H})$ \\
\hline & & $930 w$ & $\gamma(\mathrm{C}-\mathrm{H})$ \\
\hline & & $876 w$ & $\gamma(\mathrm{C}-\mathrm{H})$ \\
\hline & & $835 w$ & \\
\hline \multirow[t]{2}{*}{$777 \mathrm{~m}$} & $769 w$ & $771 \mathrm{~m}$ & $\beta_{\mathrm{a}}\left(\mathrm{COO}^{-}\right)$ \\
\hline & & $752 \mathrm{~m}$ & $\gamma(C-C)$ \\
\hline $739 m$ & $739 w$ & $732 \mathrm{~m}$ & $v(\mathrm{C}=\mathrm{S})$ \\
\hline $692 \mathrm{~m}$ & $700 w$ & & Skeletal $\mathrm{N}-\mathrm{C}-\mathrm{N}, \mathrm{C}-\mathrm{N}-\mathrm{C}, \mathrm{C}-\mathrm{C}-\mathrm{C}$ \\
\hline $640 \mathrm{~m}$ & $651 w$ & $643 w$ & Skeletal $\mathrm{N}-\mathrm{C}-\mathrm{N}, \mathrm{C}-\mathrm{N}-\mathrm{C}, \mathrm{C}-\mathrm{C}-\mathrm{C}$ \\
\hline $621 \mathrm{~m}$ & $607 w$ & $602 \mathrm{sh}$ & $\phi(C-C)$ \\
\hline 550 sh & $552 w$ & $558 \mathrm{~m}$ & $\beta_{\mathrm{a}}\left(\mathrm{COO}^{-}\right)$ \\
\hline $524 \mathrm{~m}$ & $528 w$ & $530 w$ & $\delta(\mathrm{C}-\mathrm{COO})$ out of plane \\
\hline $499 m$ & $498 w$ & $498 w$ & $\alpha(C-C-C)$ \\
\hline $436 \mathrm{~m}$ & $431 w$ & $431 w$ & $\gamma\left(\mathrm{COO}^{-}\right)$ \\
\hline
\end{tabular}

wavenumber while the $v_{\mathrm{s}}\left(\mathrm{COO}^{-}\right)$band is observed at lower wavenumber. The frequency of the asymmetric carboxylate vibration in the IR spectra, $v_{\mathrm{a}}\left(\mathrm{COO}^{-}\right)$and the magnitude of the separation between the carboxylate stretches, $\Delta=v\left(\mathrm{COO}^{-}\right)-v_{\mathrm{s}}\left(\mathrm{COO}^{-}\right)$, are often used as spectroscopic criteria to determine the carboxylate binding mode. In the present structures the $v$ is equal to $\sim 100 \mathrm{~cm}^{-1}$, while in several metal complexes with chelating coordination the $\Delta$ is about two times greater [38-40]. The weak band at $\sim 3607 \mathrm{~cm}^{-1}$, which is observed only in the spectrum of $\mathbf{3}$ could be assigned to the $v(\mathrm{OH})$ of water molecule, since the compound 3 is monohydrate. In the spectrum of the compound $\mathbf{1}$ and $\mathbf{2}$ the this band is not observed, both crystals are anhydrous.

\section{Conclusion}

This study confirms the usefulness of 1-(diaminomethylene)thiourea as a building block in the crystal engineering and demonstrates its interaction with mono-, di- and trihydroxybezoic acids forming of extended supramolecular hydrogen bonding networks. The $\mathrm{R}_{2}^{2}(8)$ hydrogen bonding motif describes the interaction between the oppositely charged units of these crystals. In 1 and 2 this motif is formed between the amine groups, as donors, joined to the same $C$ atom of the cation and the oxygen atoms of carboxylate group, whereas in $\mathbf{3}$, the $\mathrm{R}_{2}{ }^{2}(8)$ motif is created by donation of iminium and amine groups lined to the $\mathrm{C}=\mathrm{S}$ and the oxygen atoms of carboxylate group. The three-dimensional hydrogen-bonding supramolecular structure in $\mathbf{1}$ and in $\mathbf{2}$ is very similar, but different to that in the crystal 3, in which the 3,4,5-trihydroxybenzoate anions interact each other via $\mathrm{O}-\mathrm{H} \ldots \mathrm{O}$ hydrogen bonds forming two-dimensional layers that are interconnected by 1(diaminomethylene)thiouron-1-ium cations and water molecules forming three-dimensional network. The proton transfer from $\mathrm{COOH}$ group of the respective acid 1-(diaminomethylene)thiourea with the formation of 1-(diaminomethylene)thiouron-1-ium cation is demonstrated by appearance of the iminium bond vibration at $\sim 1722 \mathrm{~cm}^{-1}$. The presence of the $\mathrm{OH}$ group(s) in these crystals is manifested in the IR-spectrum as a relatively strong narrow band at wavenumber above $3400 \mathrm{~cm}^{-1}$. The wavenumber of the $v$ $(\mathrm{OH})$ correlates well with the strength of the $\mathrm{O}-\mathrm{H} \cdots \mathrm{O}$ hydrogen bonds in which the $\mathrm{OH}$ is involved. The presence of the $\mathrm{N}-\mathrm{H} \cdots \mathrm{O}$ and $\mathrm{O}-\mathrm{H} \cdots \mathrm{O}$ hydrogen bonds is manifested in the IR spectrum as a broad band between 3300 and $2700 \mathrm{~cm}^{-1}$ and in the range of $1400-1100 \mathrm{~cm}^{-1}$.

\section{Appendix A. Supplementary material}

Additional material comprising full details of the X-ray data collection and final refinement parameters including anisotropic thermal parameters and full list of the bond lengths and angles have been deposited with the Cambridge Crystallographic Data Center in the CIF format as supplementary publications no. CCDC 917240, 917242 and 917241 for 1, 2 and $\mathbf{3}$ crystals. Copies of the data can be obtained free of charge on the application to CCDC, 12 Union Road, Cambridge, CB21EZ, UK, (fax: (+44) 1223-336033; email: deposit@ccdc.cam.ac.uk), Supplementary data associated with this article can be found, in the online version, at http://dx.doi.org/10.1016/j.molstruc.2013.03.015.

\section{References}

1] J. Janczak, G.J. Perpétuo, Acta Cryst. C64 (2008) o114

[2] K. Chakrabarty, T. Kar, S.P.S. Gupta, Acta Cryst. C46 (1990) 2065

[3] M.K. Kabir, K. Yamada, K. Adachi, M. Kondo, S. Kawata, Acta Cryst. C58 (2002) m580.

[4] E. Doxiadi, R. Vilar, A.J.P. White, D.J. Williams, Polyhedron 22 (2003) 2991.

[5] G.J. Perpétuo, J. Janczak, Acta Cryst. C64 (2008) o264.

[6] J. Janczak, G.J. Perpétuo, Acta Cryst. C64 (2008) 0330.

[7] J. Janczak, G.J. Perpétuo, Acta Cryst. C65 (2009) o118.

[8] M. Hołyńska, M. Kubiak, Acta Cryst. C64 (2008) 0609.

[9] M. Hołyńska, M. Kubiak, Acta Cryst. C65 (2009) o191.

[10] M. Hołyńska, M. Kubiak, Acta Cryst. C65 (2009) o410.

[11] J. Janczak, G.J. Perpétuo, J. Mol. Struct. 975 (2010) 166.

[12] J. Janczak, G.J. Perpétuo, J. Mol. Struct. 988 (2011) 73.

[13] G.J. Perpétuo, J. Janczak, J. Mol. Struct. 1007 (2012) 74.

[14] T. Steiner, Acta Cryst. B57 (2001) 103.

[15] G.J. Perpétuo, J. Janczak, J. Mol. Struct. 1031 (2013) 14.

[16] CrysAlis CCD and CrysAlis Red, Version 171.32.6, Oxford Diffraction Poland, Wrocław, Poland, 2006.

[17] G.M. Sheldrick, SHELXS97, SHELXL97, Programs for Crystal Stuctures Solution and Refinement, University of Göttingen, Göttingen, Germany, 1997.

[18] K. Brandenburg, H. Putz, DIAMOND Version 3.0, Crystal Impact GbR, Bonn, Germany, 2006.

[19] M.C. Etter, Acc. Chem. Res. 23 (1990) 120

[20] D.R. Johnson, F.X. Powell, W.H. Kirchoff, J. Mol. Spectrosc. 39 (1971) 136.

[21] R. Fausto, L.A.E. Batista de Carvalho, J.J.C. Teixeria-Dias, M.N. Ramos, J. Chem. Soc., Perkin Trans. 2 (1989) 1945.

[22] F.H. Allen, O. Kennard, D.G. Watson, L. Brammer, A.G. Orpen, R. Taylor, J. Chem. Soc., Perkin Trans. 2 (1989) S1-S19.

[23] G.Y. Bai, H.S. Ning, J. Simpson, X.Y. Qin, N. Li, Acta Cryst. E62 (2006) o4567.

[24] F.H. Allen, C.H. Bird, R.S. Rowland, P.R. Raithby, Acta Cryst. B53 (1997) 696.

[25] F.H. Allen, C.H. Bird, R.S. Rowland, P.R. Raithby, Acta Cryst. B53 (1997) 680.

[26] F.H. Allen, Acta Cryst. B58 (2002) 380.

[27] E.A. Heath, P. Singh, Y. Ebisuzaki, Acta Cryst. C48 (1992) 1960.

[28] B. Sarma, P. Sanphui, A. Nangia, Cryst. Growth Des. 10 (2010) 2388

[29] S.W. Ng, Acta Cryst. E67 (2011) o2476.

[30] J.H. Zhao, I.A. Khan, F.R. Fronczek, Acta Cryst. E67 (2011) o316.

[31] N. Hirun, S. Saithong, C. Pakawatchi, V. Tantishaiyakul, Acta Cryst. E67 (2011) o787. 
[32] H.D. Clarke, K.K. Avova, L. Wojtas, M.J. Zaworotko, Cryst. Growth Des. 11 (2011) 964.

[33] L. Pauling, in: The Chemical Bond: A Brief Introduction to Modern Structural Chemistry, Cornell University Press, Ithaca, New York, 1967 (Chapter 3).

[34] G. Socrates, Infrared Characteristic Group Frequencies, Wiley-Interscience, Chichester, UK, 1980.

[35] G. Socrates, Infrared and Raman Characteristic Group Frequencies, third ed., Wiley, New York, USA, 2001
[36] J. Favrot, D. Vocelle, C. Sandorfy, Photochem. Photobiol. 28 (1979) 417

[37] F.H. Allen, C.M. Bird, R.S. Rowland, P.R. Raithby, Acta Cryst. B53 (1997) 680

[38] M. Nara, H. Torri, M. Tasumi, J. Phys. Chem. 100 (1996) 19812.

[39] W. Lewandowski, M. Kalinowska, H. Lewandowska, J. Inorg. Biochem. 99 (2005) 1407.

[40] V. Zeleňák, Z. Vargová, K. Györyová, Spectrochim. Acta A66 (2007) 262. 